\title{
Efeito de Atividades Antrópicas Sobre a Mata do Instituto Federal de Educação Ciência e Tecnologia Minas Gerais - campus São João Evangelista (IFMG-SJE)
}

\author{
Eduardo Felipe Ribeiro, eduardofelipeeaf@yahoo.com.br, Tecnólogo em Silvic., IFMG-SJE. \\ Paulo do Nascimento, professor do IFMG-SJE. \\ paulo.nascimento@ifmg.edu.br, Biólogo, Mestre em Meio Ambiente e Sustentabilidade \\ Aderlan Gomes da Silva, professor do IFMG-SJE. \\ aderlan.silva@ifmg.edu.br, Engenheiro Florestal, Doutor em Fitopatologia, \\ Gustavo de Almeida Santos, Tecnólogo em Silvicultura, IFMG-SJE. \\ Diêgo Gomes Júnior, Tecnólogo em Silvicultura, IFMG-SJE.
}

\section{RESUMO}

A vegetação ainda é fonte de energia para atividades de parte considerável da população. Os objetivos deste trabalho foram: constatar a extração de madeira num fragmento de Mata Atlântica do IFMG-SJE; verificar as causas dessa extração; estipular indicadores florestais que sinalizam a pressão antrópica sofrida e obter percepções básicas sobre o ambiente. Realizaram-se entrevistas orientadas nos bairros Centenários I e II e Engenho de Serra. Detectaram-se as plantas mais retiradas pelos moradores (angico, canudo-de-pito, murici e pau-jacaré), que tiveram medidas os seus diâmetros a altura o peito (DAP) em parcelas de $1000 \mathrm{~m}^{2}(50 \times 20 \mathrm{~m})$. Os DAPs foram submetidos ao teste de Tukey. Os DAPs foram medidos com uma suta e um gabarito de 1,30 m. Nos tocos remanescentes com sinais de corte e mediram-se os DAPs e encontrou-se uma classe de DAP preferencial de extração. Em função da baixa escolaridade e do baixo poder aquisitivo dos moradores, há extração de madeira nessa mata. Os DAPs e o uso de questionários foram eficazes no diagnóstico de interferência antrópica nessa mata. Envolver os moradores em projetos de educação ambiental e socioeconômico pode favorecer a proteção desse fragmento de Mata.

Palavras Chave: Degradação florestal, ambiente antropizado, educação ambiental.

\section{Effect of Human Activities on the Forest of the Federal Institute of Science and Technology Education Minas Gerais - campus São João Evangelista (IFMG-SJE)}

\begin{abstract}
The vegetation is still a source of energy for activities of a considerable part of the population. Our objectives were: to establish the logging in a fragment of Atlantic Forest IFMG-SJE; determine the causes of extraction; provide indicators that signal the forest suffered human disturbance, to obtain basic perceptions about the environment. Interviews were conducted in targeted neighborhoods Centenários I and II and Engenho de Serra. Plants were detected more withdrawals by residents (angico, canudo-de-pito, murici and pau-jacaré), which measures had their diameters at breast height $(\mathrm{DBH})$ in parcels of $1000 \mathrm{~m}^{2}(50 \times 20 \mathrm{~m})$. The DBH were submitted to Tukey's test. The DBHs were measured with a caliper and a template of $1.30 \mathrm{~m}$. In the remaining stumps with signs of cut and measured the $\mathrm{DBH}$ and found himself a preferred class of $\mathrm{DBH}$ extraction. As a function of low education and low income residents, there are logging this forest. The use of questionnaires and DBH have been effective in the diagnosis of human interference that forest. Involve residents in environmental education projects and socioeconomic may favor the protection of this forest fragment.
\end{abstract}

Keywords: Forest degradation, anthropic environment, environmental education. 


\section{INTRODUÇÃO}

Diferente da forma atual, a relação do homem com a natureza num período que antecede ao cartesianismo era dado pelo respeito e temor aos fenômenos naturais do planeta. A partir do pensamento antropocentrista, o homem passa então a destruir os recursos naturais de forma generalizada. Em relação a vegetação, - Brasil é um dos países que mais colaboraram para sua destruição, embora, num contexto global, preserve consideráveis áreas de floresta.

A abordagem sobre a Ecologia Política, tecida por Trevizan (2011), mostra que "a sociedade capitalista e o estado moderno são vistos por ele como os maiores responsáveis pela degradação dos recursos naturais". Talvez por considerar que os problemas naturais sejam naturais e até mesmo necessários é que mesmo de forma inconsciente tenha havido promoção desigual da modernização agrícola. Essa desigualdade levou os pequenos agricultores a intensificar a exploração dos recursos naturais, como forma de aumentar a produção. Assim, eliminar florestas para uso agrícola, aliada ao mau uso do solo e dos recursos hídricos, tem contribuído de forma negativa para ampliar os problemas ambientais criados pelo atual modo de produção.

A Mata Atlântica, por inserir-se no espaço mais disputado pelo crescimento populacional e econômico do Brasil, é um dos biomas mais ameaçados com a exploração desses recursos. A pressão sobre as florestas se dá pela expansão de áreas para a agropecuária, pela retirada ilegal de madeiras e mesmo para abastecimento de indústrias moveleiras. Os remanescentes desse bioma localizam-se normalmente em áreas de difícil acesso e em regiões pouco desenvolvidas economicamente. Mesmo com as fitofisionomias muitas vezes mal conservadas a Mata Atlântica é um conjunto florestal complexo, possuindo várias áreas em regeneração (Lino \& Simões, 2002).

Apesar dos atuais avanços tecnológicos, estima-se que parte considerável da população ainda utilize lenha ou outros resíduos vegetais como fonte de energia para atividades ligadas à sua subsistência e isso pode afetar a biodiversidade remanescente, através da fragmentação florestal que atinge a maior parte dos biomas brasileiros (Pereira, et al., 2003).

Entre as espécies arbóreas predominantes na área de fragmento florestal com domínio de Mata Atlântica, podemos citar: Angico, Canudo-de-pito, Pau-jacaré e Murici (Nunes et al., 2003). O angico (Anadenathera $s p)$, Mimosoideaceae, possui madeira pesada, ótima para lenha e carvão. Apresenta frequência elevada e padrão de dispersão descontínua e irregular. Ocorre principalmente em formações primárias e secundárias, em solos bem drenados, aonde chega a formar populações quase puras, produzindo grande quantidade de sementes viá- veis. (Lorenzi, 2002).

O canudo-de-pito (Mabea fistulifera) é uma Euphorbiaceae nativa, lactescente e arbórea (Vieira et al., 1997). Para Lorenzi (2002) essa espécie é pioneira típica de vegetação secundária, de terrenos arenosos com baixa fertilidade e alta acidez. Ocorre normalmente agregada em bordas de matas e em locais muito antropiza-dos, raramente encontrada isolada e no interior de mata primária densa.

Byrsonima sericea é uma Malpighiaceae arbustiva conhecida como murici, possui copa ovalada e densa, casca áspera e pode atingir $16 \mathrm{~m}$ de altura. Tem preferência por solos argilosos e férteis ao longo de rios e córregos, também ocorre em capoeiras e beiras de matas e capões (Lorenzi, 2002).

Piptadenia gonoacantha (pau-jacaré) é pioneira a secundária inicial, que ocorre de Minas Gerais a Santa Catarina, quase que exclusivamente em associações secundárias como capoeiras, em solos de fertilidade variada (Carvalho, 1999). Possui tronco normalmente tortuoso, com cristas aculeadas por toda sua extensão. Sua casca possui cristas lineares longitudinais interligadas por outras menores transversais, lembrando o couro de jacaré, motivo de seu nome. A madeira é de baixa resistência e altamente susceptível ao ataque de térmitas (Trevisan et al., 2003). Segundo Lorenzi (2002), é uma das melhores madeiras para carvão e lenha.

A educação ambiental é instrumento básico e indispensável para sustentabilidade dos processos de preservação ambiental. Para Zaneti et al. (2002) existe uma insustentabilidade da estrutura sócio-ambiental das cidades, tanto das relações entre as pessoas, como das relações das pessoas com a natureza. Para que essas relações sejam viáveis, é necessário que haja uma educação ambiental integrada que proporcione as condições necessárias para a produção de conhecimentos e habilidades, visando à participação coletiva na gestão do uso de recursos naturais.

Características particulares tornam certas espécies de plantas mais susceptíveis a extração. Acredita-se que populações humanas, circunvizinhas de remanescentes florestais, utilizem diferenciadamente os recursos florestais.

Os objetivos deste trabalho foram: constatar e verificar as causas da extração de madeira na Mata do IFMG-SJE; detectar as espécies de plantas mais retiradas pelos moradores do entorno dessa mata; obter percepções básicas de conservação ambiental dos moradores; diagnosticar a finalidade das madeiras extraídas; constatar as condições socioeconômicas dos moradores e estipular critérios que sinalizem a pressão antrópica sofrida por esse fragmento de Mata Atlântica. 


\section{METODOLOGIA}

Este trabalho foi desenvolvido num fragmento de Mata Atlântica (Figura 1), do Instituto Federal de
Educação, Ciência e Tecnologia Minas Gerais (IFMGSJE), no município de São João Evangelista, aqui denominado Mata do IFMG-SJE, no período de abril de 2008 a maio de 2009.

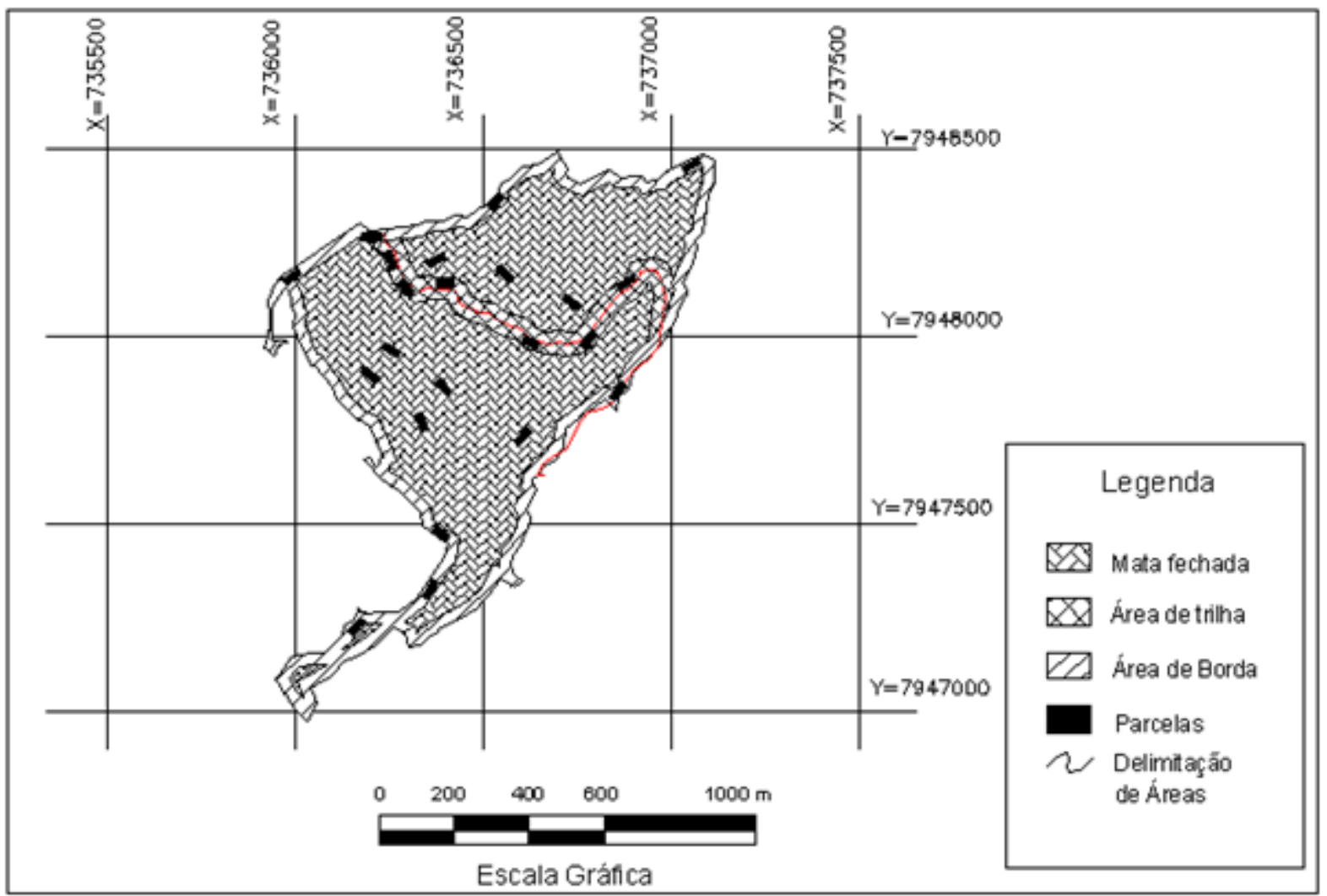

Figura 1 - Mapa da mata do IFMG-SJE com as divisões de áreas e suas respectivas parcelas alocadas neste experimento.

A Mata do IFMG-SJE possui aproximadamente 80,00 hectares (Scolforo et al., 2008), confronta, dentro do campus, com plantações e pastagens e externamente com residências do bairro Engenho de Serra (Pombal) e com uma fazenda de exploração pecuária. Esse município fica na região Centro Nordeste de Minas Gerais, no Vale do Rio Doce, mais especificamente na Bacia do Suaçuí, próximo aos vales do Jequitinhonha e Mucuri (IBGE, 2009). O clima nessa região é segundo Köppen - (2010) Aw - Tropical Continental com chuvas de verão e inverno seco. A temperatura média anual é de $22^{\circ} \mathrm{C}$, a precipitação média anual é de $1.180 \mathrm{~mm}$ e a altitude média é de 680m (portalsjevanjelista, 2009).

Realizaram-se noventa entrevistas, orientadas por um questionário, com moradores dos bairros Engenho de Serra e Centenários (I e II), escolhidos em função de sua proximidade com a Mata do IFMG-SJE.

Processou-se em percentagem os dados relativos às espécies de plantas mais utilizadas pela população, a fim de constatar as espécies mais retiradas da mata pelos moradores. Dentro da mata, em 22 parcelas georreferenciadas de $1000 \mathrm{~m}^{2}(50 \times 20 \mathrm{~m})$, mediu-se, através de uma suta e um gabarito de $1,30 \mathrm{~m}$, o Diâmetro à Altura do Peito (DAP) dos indivíduos acima de $2,5 \mathrm{~cm}$ diâmetro, dessas espécies.

As parcelas foram lançadas a uma distância mínima de $30 \mathrm{~m}$, segundo ao método de amostragem em dois estágios, que consiste na divisão da população em unidades de primeiro estágio, com determinada homogeneidade (Soares et al., 2006). Essas unidades foram subdivididas em unidades de segundo estágio (parcelas), definidas pelo método de amostragem a esmo ou sem norma, um tipo de amostragem não probabilística (Costa Neto, 1977).

Na Mata do IFMG-SJE as unidades de primeiro e segundo estágio foram: área de borda (16,25 ha) com oito parcelas ( $5 \%$ dessa área); áreas de acesso à mata via trilhas $(6,47$ ha) com seis parcelas (10\% dessa área) e áreas de mata fechada sem acesso por trilhas $(54,96$ ha) com oito parcelas (1,5\% dessa área).

Durante a coleta de dados, também se obteve o diâmetro de tocos remanescentes de árvores, com sinais de corte, encontrados ao longo da mata, independente de ocorrerem ou não nas parcelas alocadas. Não foi possível saber de quais espécies eram os tocos restantes das plantas cortadas, mas a partir deles 
obteve-se um intervalo de diâmetro preferencial de extração (classe) das plantas. Salienta-se que a classe de diâmetro preferencial trata-se de uma aproximação, pois os tocos remanescentes estavam a cerca de $50 \mathrm{~cm}$ do solo e os DAPs foram tomados a 1,30 m e dependendo da conicidade da árvore, pode haver uma maior ou menor interferência na diferença dos diâmetros. A partir da classe de diâmetro preferencial e dos DAPs obtidos para as quatro espécies, formaram-se as demais classes de DAP.

Os dados obtidos nas entrevistas orientadas foram tabulados e em função das características dos dados e dos objetivos deste trabalho, optou-se pela análise unidimensional dos dados. Segundo Auricchio (2003), essa análise é simples e consiste na tabulação das respostas com resultados em percentuais e plotados em tabelas, fornecendo parâmetros para a discussão e interpretação dos dados.

Fez-se por local (trilha, mata fechada e borda) e por espécies mais exploradas (angico, murici, pau-jacaré e canudo-de-pito) as médias dos DAPs. Comparou-se essas médias entre os locais e entre as espécies pelo teste de Tukey ao nível de $5 \%$ de significância, após a realização da ANOVA dos DAPs recolhidos. Utilizou-se o software SAEG (SAEG, 2007) para o tratamento estatístico dos dados.

\section{RESULTADOS E DISCUSSÃO}

A baixa escolaridade dos pais e uma melhora na escolaridade dos filhos em reação aos pais (Tabela 1) indicam conscientização das pessoas em relação à importância da educação formal em suas vidas.

Tabela 1 - Escolaridade dos moradores (pais e filhos) entrevistados por bairro.

\begin{tabular}{|c|c|c|c|c|}
\hline & \multicolumn{4}{|c|}{ Bailros } \\
\hline & eentenáriol & eentenánioll & Engenho de Serra & Média (\%) \\
\hline \multicolumn{5}{|c|}{ Escolaridade pais (\%) } \\
\hline $1^{a}$ a $4^{a}$ série & 82,2 & 73,3 & 66,7 & 74,1 \\
\hline Fundamental & - & 6,7 & 13,3 & 6,7 \\
\hline Médio & 17,8 & 20,0 & 13,3 & 17,0 \\
\hline Superior & - & - & 6,7 & 2,2 \\
\hline \multicolumn{5}{|c|}{ Escolaridade filhos (\%) } \\
\hline $1^{\mathrm{a}}$ a $4^{\mathrm{a}}$ série & 39,2 & 33,3 & 19,3 & 30,6 \\
\hline Fundamental & 30,4 & 46,6 & 42,0 & 39,7 \\
\hline Médio & 26,1 & 13,3 & 25,8 & 21,7 \\
\hline Superior & 4,3 & 6,8 & 12,9 & 8,0 \\
\hline
\end{tabular}

Para Gomes \& Sparta (2005) o interesse por educação parece consolidado entre os jovens. A baixa renda familiar (até dois salários mínimos) declarada por $82,2 \%$ dos entrevistados (Tabela 2 ) e a baixa escolarida- de da maioria dos pais indicam o baixo poder aquisitivo da população entrevistada. Para IBGE (2009), o acesso a bens e serviços básicos depende quase que exclusivamente do nível de renda atingido pelas famílias.

Tabela 2 - Número de moradores por residência e renda familiar por bairro em \%.

\begin{tabular}{|c|c|c|c|c|c|c|c|c|}
\hline \multirow{2}{*}{ Bairro } & \multicolumn{4}{|c|}{ Número de moradores por residência } & \multicolumn{4}{|c|}{ Renda familiar (salário mínimo) } \\
\hline & Até 2 & 3 a 5 & 6 a 8 & Mais de 8 & Menos de 1 & De 1 a 2 & De 2 a 4 & Mais de 4 \\
\hline Centenário I & 13,3 & 73,3 & 13,3 & - & 20,0 & 66,7 & 13,3 & - \\
\hline Centenário II & 20 & 60 & 13,3 & 6,7 & 13,3 & 86,7 & - & - \\
\hline Engenho de Serra & 20 & 50 & 30 & - & 6,7 & 53,3 & 40,0 & - \\
\hline Média & 17,8 & 61,1 & 18,9 & 2,2 & 13,3 & 68,9 & 17,8 & - \\
\hline
\end{tabular}

Em média $62,3 \%$ dos entrevistados utilizavam lenha em suas atividades. Destes $(34,4 \%)$ utilizam-na há mais de 10 anos (Tabela 3 ). Esses dados consonam com os de Botrel et al. (2006) segundo os quais consumir lenha como combustível (energia) relaciona-se ao fator econômico da população. A extração de madeira na Mata do IFMG-SJE ocorre em função do baixo poder aquisitivo da população. Durante as entrevistas vários moradores afirmaram usar lenha para reduzir gastos com energia elétrica e gás de cozinha. 
Tabela 3 - Tempo de utilização de lenha pelos moradores entrevistados por bairro.

\begin{tabular}{|c|c|c|c||c|}
\hline \multirow{2}{*}{ Tempo (anos) } & \multicolumn{3}{|c|}{ \% de resposta/bairro } & \multirow{2}{*}{ Média } \\
\cline { 2 - 5 } & Centenário I & Centenário II & Engenho de Serra & 15,6 \\
\hline 1 a 3 & - & 20,0 & 26,7 & 6,7 \\
\hline 3 a 6 & - & 6,7 & 13,3 & 5,6 \\
\hline 6 a 10 & 6,7 & - & 10,0 & 34,4 \\
\hline Mais de 10 & 46,7 & 33,3 & 23,3 & 62,3 \\
\hline Total de usuários & 53,4 & 60,0 & 73,3 & 13,3 \\
\hline Não utiliza mais & 20,0 & 13,3 & 6,7 & 24,5 \\
\hline Nunca utilizou & 26,7 & 26,7 & 20,0 & \\
\hline
\end{tabular}

As características socioeconômicas da população podem influir diretamente na maneira como eles agem em relação à mata. Para Silva et al. (2003), as dificuldades sócio-econômicas criam uma condição adversa à percepção ambiental pelos indivíduos, conduzindo-os a desenvolver condutas e ações degradadoras do ambiente.

A partir da percepção do meio ambiente pelos moradores estabelece-se um entendimento das relações entre eles e o ambiente circundante. Para Pelissari et al. (2004), percepção ambiental é a tomada de consciência do ambiente pelo homem, é o ato de perceber o ambiente em que está inserido, aprendendo a proteger e a cuidar desse ambiente. Para esses autores um desafio à proteção dos fragmentos florestais é a existência de diferentes percepções sobre valores e sua importância entre os indivíduos de culturas ou grupos sócio-econômicos diferentes.

Para $62,2 \%$ dos entrevistados, a Mata do IFMGSJE é essencial para a vida da fauna e flora local e para a qualidade de vida da população (Tabela 4). Para 4,4\% deles a percepção sobre a mata baseia-se na capacidade dela fornecer recursos às pessoas, gerando uma visão utilitarista da natureza. Para Camargo et al. (2008), o olhar utilitarista faz as pessoas serem a favor da preservação das matas por elas lhes fornecer recursos materiais.

Tabela 4 - Percepção ambiental da Mata do IFMG-SJE segundo os moradores entrevistados por bairro.

\begin{tabular}{|c|c|c|c|c|}
\hline \multirow[b]{2}{*}{ Percepção } & \multicolumn{3}{|c|}{ Bairros } & \multirow[b]{2}{*}{ Média (\%) } \\
\hline & $\begin{array}{c}\text { Centenário I } \\
(\%)\end{array}$ & $\begin{array}{c}\text { Centenário II } \\
(\%)\end{array}$ & $\begin{array}{l}\text { Engenho de Ser- } \\
\text { ra (\%) }\end{array}$ & \\
\hline $\begin{array}{l}\text { Local que fornece recursos florestais } \\
\text { e animais }\end{array}$ & - & 6,7 & 6,7 & 4,4 \\
\hline $\begin{array}{l}\text { Local de beleza rara por estar tão per- } \\
\text { to de uma área urbana }\end{array}$ & 46,7 & 33,3 & 20,0 & 33,3 \\
\hline $\begin{array}{c}\text { Essencial para vida de espécies da } \\
\text { fauna e flora e qualidade de vida da } \\
\text { população }\end{array}$ & 53,3 & 60,0 & 73,3 & 62,2 \\
\hline
\end{tabular}

A maioria dos entrevistados $(88,9 \%)$ não contribui de forma direta para a conservação da mata, mas tem vontade de vê-la conservada e por isso aprovam a idéia de se adotar mecanismos para sua conservação
(Tabela 5). Para eles, a mata é importante, mas eles não sabiam argumentar satisfatoriamente suas posições. Segundo eles "ela é purificadora do ar" ou "evita o efeito estufa" e por isso deve ser conservada.

Tabela 5 - Contribuição dos entrevistados para a conservação da Mata do IFMG-SJE por bairros. 
Efeito de Atividades Antrópicas Sobre a Mata do Instituto Federal de Educação Ciência e Tecnologia Minas Gerais - campus São João Evangelista (IFMG-SJE)

Tabela 5 - Contribuição dos entrevistados para a conservação da Mata do IFMG-SJE por bairros.

\begin{tabular}{|c||c|c||c||c|}
\hline \multicolumn{2}{|c|}{ Contribuição } & \multicolumn{2}{|c||}{ Porcentagem de respostas por bairros } & \multirow{2}{*}{ Média (\%) } \\
\cline { 2 - 5 } & Centenário I & Centenário II & Engenho de Serra & \\
\hline $\begin{array}{c}\text { De alguma maneira contribui para sua } \\
\text { conservação }\end{array}$ & 6,7 & - & 16,7 & 7,8 \\
\hline $\begin{array}{c}\text { Não contribui, mas tem vontade de vê- } \\
\text { la conservada }\end{array}$ & 93,3 & 100,0 & 73,3 & 88,9 \\
\hline Não tem interesse na sua conservação & - & - & 10,0 & 3,3 \\
\hline
\end{tabular}

No Bairro Engenho de Serra, $10 \%$ dos entrevistados não tem interesse na conservação da Mata do IFMG-SJE. Segundo Camargo et al. (2008) pessoas sem interesse em conservar os remanescentes enxergam as matas como algo inútil, sem sentido na vida delas. Elas preferem viver o seu bairro, lócus "civilizado", urbano.

Silva et al. (2003), em trabalho sobre percepção ambiental com moradores do povoado de Guabiraba em Recife-PE, encontraram $26,6 \%$ das respostas à pergunta: "como preservar a mata de Dois Irmãos?" como sendo: "não sabiam como preservar a mata". Outras respostas foram: "fiscalizando" $18,3 \%$ e "não desmatando" $16,6 \%$.

Percebe-se uma relação de "intimidade" dos moradores do bairro Engenho de Serra com a Mata do IFMG-SJE (Tabela 6).

\begin{tabular}{|c||c|c||c||c|}
\hline \multirow{2}{*}{ Contribuição } & \multicolumn{3}{|c||}{ Porcentagem de respostas por bairros } & \multirow{2}{*}{ Média (\%) } \\
\cline { 2 - 5 } & Centenário I & Centenário II & Engenho de Serra & \\
\hline sim & 20,0 & 26,7 & 66,7 & 37,8 \\
\hline não & 80,0 & 73,3 & 33,3 & 62,2 \\
\hline
\end{tabular}

Afirmaram conhecer o interior dessa mata $66,7 \%$ dos moradores, no entanto, só nesse bairro detectou-se (Tabela 5) morador sem interesse em preservar esse fragmento de mata.

Em campo constataram-se cercas destruídas e/ ou a sua inexistência em certos pontos da área limítrofe da mata com a cidade, possibilitando o livre trânsito de moradores e animais domésticos à mata, além de servir de passagem para o escoamento de lenha extraída. Mediante essa realidade constatada, a questão relevante que se coloca é: será possível conservar uma mata praticamente urbana apenas com vigilância e controle de acesso a essa mata?

Em um estudo sobre a percepção ambiental de visitantes do parque Estadual da Serra do Rola Moça, em Minas Gerais, Jacobi et al. (2004) verificaram que a maioria dos grupos estudados considera desvantajoso o fato de uma reserva se situar próximo a centros urbanos. Para Serrão (2002), a preservação de uma floresta depende da participação dos moradores do entorno e dos visitantes.

Para proteção do remanescente em estudo acredita-se que a atuação do IFMG-SJE para além dos perímetros legais de sua mata seja imprescindível. É necessário construir laços afetivos entre os moradores e a mata, principalmente entre os que a utilizam como fonte de lenha. Nesse sentido, ações efetivas de educação ambiental do IFMG-SJE e da prefeitura de São João Evangelista (PMSJE) precisam integrar a comunidade e o remanescente, com o propósito de garantir de fato a conservação do mesmo. Deve-se compatibilizar a necessidade de extrativismo (lenha) de alguns moradores (aspectos sócio-econômicos) com a conservação do remanescente (aspectos educativo-conservacionistas) de Mata Atlântica em estudo.

Os dados obtidos no presente trabalho como triIhas e clareiras no interior da mata; sinais de ferramentas em troncos de árvores; pedaços de troncos de árvores cortadas e a presença de espécies características de área de mata em recuperação (pioneiras ou "plantas de sol"), tais como cipós, bambus, imbaúbas e canudode-pito, possibilitam afirmar que existem intervenções humanas no fragmento estudado.

Boa parte das intervenções constatadas em campo neste trabalho consonam com Gomes et al. (2004), segundo os quais a presença de bambus caracteriza floresta explorada e exploração seletiva, abertura de clareiras e outras interferências antrópicas, podem aumentar a incidência de cipós nos fragmento florestais. O canudo-de-pito, apesar de explorado, é um importante indicador de pressão antrópica, pois segundo Pereira (2007) essa espécie é normalmente encontrada agregada em bordas ou em áreas com impacto antrópico acentuado.

Não houve diferenças estatísticas significativas entre as médias dos diâmetros das espécies, quando se considera apenas o local onde as plantas se encontram na mata (Tabela 7 ). Isso implica na retirada 
indiscriminada das espécies, independente do local, quando elas atingem determinado diâmetro na mata.

Tabela 7 - No de indivíduos e médias dos DAPs $(\mathrm{cm})$ por local.

\begin{tabular}{|c|c|c|}
\hline Locais & $\mathrm{N}^{0}$ de indivíduos & Médias (cm) \\
\hline Mata Fechada & 95 & $19.2 \mathrm{~A}$ \\
\hline Borda & 191 & $17.4 \mathrm{~A}$ \\
\hline Trilha & 160 & $16.5 \mathrm{~A}$ \\
\hline
\end{tabular}

A partir do diâmetro de tocos remanescentes de árvores com sinais de corte, encontrados ao longo da mata, obteve-se um intervalo de diâmetro preferencial de extração das plantas $(10,7$ a $24,5 \mathrm{~cm})$, com média de $17,6 \mathrm{~cm}$. Essa média é a mesma encontrada para os DAPs nos diferentes locais da mata, quando se somam todos os indivíduos encontrados nas parcelas. Isso indica, a rigor, que todas as plantas encontradas estão susceptíveis ao corte uma vez que o DAP médio delas é o mesmo que aquele encontrado para os tocos remanescentes.

Não foi possível saber de quais espécies eram os tocos remanescentes das plantas cortadas, e não foram investigados os motivos da preferência por esse DAP, mas pressupõe-se ser pela facilidade de transporte das plantas retiradas até as residências dos extratores.

Constatar diferentes diâmetros de espécies vegetais em determinado fragmento de mata num dado momento possibilita vislumbrar o processo natural de recomposição da vegetação, mas também a percepção da extração aleatória ou não de determinadas espécies em função de determinado interesse do extrativista. Relacionar DAPs com a extração de determinadas espécies, pode indicar qual delas é mais explorada num determinado ambiente em algum momento. Presença de muitos DAPs baixos, sinaliza regeneração, mas também que os DAPs ausentes podem ter sido explorados, não garantindo a recomposição esperada nos diferentes estágios subseqüentes de desenvolvimento populacional de determinada espécie. DAPs um pouco maiores ausentes significam que plantas com um padrão médio de DAP bons para a exploração foram suprimidas da vegetação. Além disso, ausência ou redução do número de indivíduos com determinados DAPs podem indicar extração ou outros fenômenos antrópicos ou naturais passados, manifestados na estrutura atual da comunidade vegetal.

As diferenças estatísticas nos DAPs verificadas entre as espécies (Tabela 8) devem estar refletindo aspectos fenológicos naturais das espécies. Murici e angico devem ser ainda plantas jovens em função dos DAPs médios encontrados, pois segundo Lorenzi (2002), Byrsonima sericea (murici) e Anadenathera $s p$ (angico) pode chegar, respectivamente, a 70 e $80 \mathrm{~cm}$ de diâmetro. Mabea fistulifera (canudo-de-pito), pode ter DAP com até $30 \mathrm{~cm}$ (Vieira et al., 1997) Piptadenia gonoacantha (pau-jacaré) pode chegar a $50 \mathrm{~cm}$ de DAP (Trevisan et al., 2003).

Tabela 8 - Comparação das médias dos DAPs das espécies encontradas no fragmento de mata.

\begin{tabular}{|l|c|c||}
\hline \multicolumn{1}{|c|}{ Espécies } & $N^{\circ}$ de indivíduos & Médias dos DAPs (cm) \\
\hline \hline Murici & 28 & $27.4009 \mathrm{~A}$ \\
\hline Angico & 130 & $19.8823 \mathrm{~B}$ \\
\hline Pau-jacaré & 89 & $15.7921 \mathrm{BC}$ \\
\hline \hline Canudo-de-pito & 145 & $14.8614 \quad \mathrm{C}$ \\
\hline Médias seguidas de mesma letra não se diferem pelo teste de Tukey a 5\% significância. \\
\hline
\end{tabular}

Os diâmetros das espécies, tomados individualmente nas parcelas, foram reunidos por local e separados por classe de diâmetro (Tabela 9). Uma das classes $(10,7$ a $24,5 \mathrm{~cm})$ contém a média dos tocos remanescentes $(17,6 \mathrm{~cm})$ medidos na mata, independente das parcelas. Essa classe é formada pelo desvio padrão $(6,9$ $\mathrm{cm})$ no entorno da média dos tocos remanescentes. que nas trilhas, praticamente em todas as classes de DAPs. Esses números são discrepantes quando se compara os DAPs entre 40 e $60 \mathrm{~cm}$. É necessário investigar mais o problema, mas há sinalização de que a presença de árvores grandes na borda exerce um efeito tampão sobre os extratores das plantas, protegendo-os da extração que ocorre normalmente no interior da mata. 
Tabela 9 - Número de indivíduos por local em cada classe de diâmetro.

\begin{tabular}{|c|c|c|c|c|c|c|}
\hline \multirow{2}{*}{ Local } & \multicolumn{5}{|c|}{ Classes de diâmetro $(\mathrm{cm})$} & \multirow{2}{*}{$\begin{array}{c}\text { Total de indivíduos } \\
\text { por local }\end{array}$} \\
\hline & $2,5-10,7$ & $10,7-24,5$ & $24,5-40$ & $40-60$ & $60-80$ & \\
\hline Borda & 80 & 66 & 34 & 10 & 1 & 191 \\
\hline Trilha & 41 & 44 & 18 & 2 & 1 & 106 \\
\hline Mata fechada & 23 & 53 & 11 & 5 & 3 & 95 \\
\hline Total de indivíduos & 144 & 163 & 63 & 17 & 5 & 392 \\
\hline
\end{tabular}

Na borda há um número elevado de indivíduos na classe de 2,5 a $10,7 \mathrm{~cm}$ e em todos locais há poucos indivíduos na última classe de diâmetro, indicando estar esta mata sempre nos estágios iniciais regeneração das plantas, pois apesar da extração o banco de sementes é mantido. É preciso estudos continuados na Mata do IFMG-SJE, a fim se verificar os quantitativos populacionais ao longo dos tempos, para cada classe de diâmetro. Segundo Nunes et al. (2003) geralmente florestas maduras apresentam maior número de árvores com áreas basais grandes (próximo do diâmetro máximo da espécie), enquanto aquelas em estádios mais iniciais de regeneração, formam grandes adensamentos de árvores finas.

Nas trilhas observa-se, a partir da segunda classe, um número gradativamente decrescente de indivíduos nas classes de maior diâmetro. Resultados esperados, uma vez que o acréscimo de biomassa nas áreas sob mata é menor em função da menor disponibilidade interna de luz. Embora na área de borda seja maior o número de indivíduos na penúltima classe em relação às outras áreas, entende-se que os exemplares de planta com diâmetros maiores, que persistem vivos na borda, tenham tido tempo suficiente para atingir o porte verificado, encontrando condições que favoreceram esse crescimento. Áreas de borda podem incrementar localmente área basal de indivíduos devido à maior incidência de luz
(Nunes et al., 2003).

De forma geral verifica-se, a partir da segunda classe de diâmetros, que o número total de indivíduos cai. Apenas $5,6 \%$ deles localizam-se nas duas últimas classes (Tabela 9). Isso indica que a mata encontra-se em processo de sucessão ecológica, não sendo, portanto uma mata remanescente original. Para Nunes et al. (2003) áreas que sofreram perturbações severas, possuem maior densidade de árvores finas e as áreas que sofreram distúrbios mais leves apresentam maior densidade de árvores altas e grossas, indicando estádio regenerativo avançado.

Para $91,4 \%$ dos moradores a madeira extraída tinha fins energéticos (Tabela 10). Apenas 8,6\% dos entrevistados usavam-na de forma estrutural (cercas, caibros e vigas para construção). Esses dados confirmam a exploração de madeira na Mata do IFMG-SJE e indiretamente pressão antrópica sobre os demais organismos dependentes desse fragmento florestal. Para Pereira et al. (2003) a exploração de subsistência afeta a fauna e a flora de um remanescente de vegetação colocando em risco a biota local. Para esses autores é possível minimizar a exploração dos remanescentes, a curto e médio prazo, através de ações de natureza educativo-ambiental na comunidade do local.

Tabela 10 - Destino dado à madeira extraída pelos moradores por bairro.

\begin{tabular}{|l||c|c|c||c|}
\hline \multirow{2}{*}{ Finalidade da madeira } & \multicolumn{3}{c||}{ \% de uso por bairro } & \multirow{2}{*}{$\begin{array}{c}\text { Média de consumo } \\
\text { (\%) }\end{array}$} \\
\cline { 2 - 5 } & Centenário I & Centenário II & Engenho de Serra & 91,4 \\
\hline Lenha & 100 & 90,9 & 83,3 & 8,6 \\
\hline Estrutural & - & 9,1 & 16,7 & - \\
\hline Móveis & - & - & - & - \\
\hline Comércio & - & - & - & - \\
\hline
\end{tabular}

\section{CONCLUSÃO}

Avaliando informações e imagens coletadas em campo constatam-se a retirada de madeira na Mata do IFMG-SJE, principalmente para fins energéticos, sendo de baixa expressão seu uso para fins estruturais. Os moradores extraem lenha da mata em função de seu baixo poder aquisitivo e percebem essa mata como importante na qualidade de suas vidas.

O uso dos DAPs das espécies mais exploradas pelos moradores, associado às entrevistas orientadas por questionário e as imagens serviram como indicadores de pressão antrópica sobre esse fragmento de 
mata, visto que a partir deles confirmou-se a pressão sofrida por essa mata. Essa pressão ocorre em função de uma DAP médio independente do local (borda, trilha e mata fechada) de extração.

O envolvimento dos moradores em projetos de educação socioambiental deve ser garantido a fim de proteger a Mata do IFMG-SJE, que merece atenção institucional, principalmente do campus onde se encontra inserida.

\section{REFERÊNCIAS BIBLIOGRÁFICAS}

AURICCHIO, A. L. R, Diagnóstico socioambiental: subsídios para a formação do corredor ecológico Cantareira-Mantiqueira. Ubatuba, Instituto Pau Brasil de História Natural, relatório técnico, n. 32003.

BOTREL, R. T.; RODRIGUES L. A.; GOMES, L. J.; CARVALHO, D. A.; FONTES, M. A. L. Uso da vegetação nativa pela população local no município de Ingaí, MG, Brasil. Acta Botânica Brasílica, São Paulo, v. 20, n. 1, p. 143-156, 2006.

CAMARGO, L. J. de; LUCA, A. Q. de; SILVA, J. P. da. Representações Sociais Acerca do Meio Ambiente de Moradores do Entorno de uma Unidade de Conservação em Campinas-SP. In: ENCONTRO NACIONAL DA ANPPAS, IV, 2008, Brasília - DF. Brasília: 2008, p. 1-17.

CARVALHO, M.M.; FREITAS, V.P.; XAVIER, D. F. Comportamento de cinco leguminosas arbóreas exóticas em pastagem formada em latossolo vermelho-amarelo de baixa fertilidade. Revista Árvore, Viçosa-MG, v. 23, n. 2, p.187-192, 1999.

COSTA NETO, P. L. O. Estatística. São Paulo: Edgard Blücher, 1977.

GOMES, A. P. A; SOUZA, A. L. de; NETO, J. A. A. M.; Alteração estrutural de uma área florestal explorada convencionalmente na bacia do Paraíba do Sul, Minas Gerais, nos domínios de floresta atlântica. Revista Árvore, Viçosa-MG, v.28, n.3, p. 407-417, 2004.

GOMES, W.; SPARTA, M.; Importância atribuída ao ingresso na educação superior por alunos do ensino médio. Revista Brasileira de Orientação Profissionalizante. São Paulo, v. 6, n.2, p. 45-53, 2005.

IBGE. Instituto brasileiro de geografia e estatística. 2009. Disponível em: <http://www.ibge.gov.br/home/ estatistica/populacao/estimativa2009/POP2009_DOU. pdf> Acesso em: 24 de outubro de 2010.

JACOBI, C. M. et al. Percepção ambiental em unidades de conservação: experiência com diferentes grupos etários no Parque Estadual da Serra do Rola Moça, MG. In: ENCONTRO DE EXTENSÃO DA UFMG, 7, 2004, Belo Horizonte: 2004, p. 1-7.

KÖPPEN. 2010. Classificação climática de köppen. Disponível em: <http://pt.shvoong.com/socialscien-
ces/education/2001431cassifica\%C3\%A7\%C3\%A3 o-clim\%C3\%A1tica-k\%C3\%B6ppen/>. Acesso em: 15/11/2010.

LINO, C, F; SIMÕES, L, L. Sustentável Mata Atlântica: a exploração de seus recursos florestais. São Paulo-SP, Senac, 2002, 215p.

LORENZI, H. Árvores brasileiras. Nova Odessa: Plantarum, 2002. 352p.

NUNES, Y.R.F. et al. Variação da fisionomia, diversidade, e composição de guildas da comunidade arbórea em um fragmento de floresta estacional semidecidual em Lavras, MG. Acta Botânica Brasílica, São Paulo, v. 17, n. 2, p. 213-229, 2003.

PELISSARI, V. B.; FERNANDES, R. ; SOUSA, V. J. . Uso da Percepção Ambiental como Instrumento de gestão em aplicações ligadas às áreas educacional, social e ambiental. Revista Científica UNIVIX, Vitória, v. 2, p. 33-45, 2004.

PEREIRA, F. E. de A. Biodiesel produzido a partir do óleo de sementes de Mabea fistulifera Mart. 2007. 100 f. Dissertação (Mestrado) apresentada ao Programa de pós-graduação em Agroquímica da Universidade Federal de Viçosa, Viçosa-MG, 2007.

PEREIRA, R. F; PENGEL, H. O; MELO, C. C. O impacto ambiental da exploração florestal de subsistência na fauna de primatas. Brasil Florestal, n. 78, p. 61-65, dez. 2003.

PORTALSJEVANGELISTA. 2009. Disponível em: <http:// www.portalsjevangelista.com.br/historia.asp\#>. Acesso em: 17/10/2009.

PROCHNOW, M. Onde fica a mata? 2006. Disponível em: <www.apremavi.org.br/mata-atlantica/>. Acesso em: 15 de Maio 2008.

SAEG - Sistemas de análises estatísticas e genéticas. Viçosa, MG: UFV, Fundação Arthur Bernardes (versão 9.1), 2007.

SCOLFORO, J. R.; MELLO, J. M.; SILVA, C. P. C. Floresta estacional semidecidual e ombrófila: florística, estrutura, diversidade similaridade distribuição diamétrica e d altura, volumetria, tendências de crescimento e áreas aptas para manejo florestal. Lavras: UFLA, 2008.

SERRÃO, S. M. Para além dos domínios da mata: uma discussão sobre o proาcesso de preservação da reserva da Mata Santa Genebra, Campinas SP. 2002, 256 p. Tese (Doutorado) apresentada à faculdade de Educação da UNICAMP. Campinas: SP, 2002.

SILVA, C. W. M.; LYRA, L. H. B.; CORTEZ, J. S. Educação ambiental contribuindo para a preservação da mata de dois irmãos, Recife-PE. Revista eletrônica do mestrado em educação ambiental, Rio Grande - RS, v. 11, p. 2-13, jul.-dez. 2003. 
SOARES, B. P. C; NETO, P. F; SOUZA, L. A. Dendrometria e Inventário Florestal. Viçosa - MG, UFV, 2006, $276 p$.

TREVIZAN, S. D. P. Para compreender as relações sociedade-natureza e os processos de degradação ambiental. REDE - Revista eletrônica do prodema, Fortaleza, v.6, n. 1, p. 68-83, mar. 2011.

TREVISAN, H.; NADAI, J.; LUNZ, A. M; CARVALHO, A. G. de. Ocorrência de térmitas subterrâneas (Isóptera: Rhinotermitidae e Termitidae) e durabilidade natural de cinco essências florestais. Ciência Florestal, Santa Maria, v. 13, n. 2, p. 153-158, 2003.

VIEIRA, R. M.; LIMA, E. F.; BATISTA, F. A. S. Diagnósticos e perspectivas da mamoneira no Brasil. In: reunião temática matérias-primas oleaginosas no Brasil - diagnósticos, perspectivas e prioridades de pesquisa. Embrapa-CNPA/MAA/ABIOVE. Campina Grande, p.139$150,1997$.

ZANETI, I. C. B. B.; SÁ, L. M. A educação ambiental como instrumento de mudança na concepção de gestão dos resíduos sólidos domiciliares e na preservação do meio ambiente. In: ENCONTRO ASSOCIAÇÃO NACIONAL DE PÓS-GRADUAÇÃO E PESQUISA EM AMBIENTE E SOCIEDADE, 1, 2002, Indaiatuba, 2002 p. 1-10. Acesso em: 14 de jan. 2011. Online. Disponível em: <http://www.anppas.org.br/encontro_anual/encontro1/gt/sociedade_do_conhecimento/Zaneti\%20-\%20 Mourao.pdf $>$. 